\title{
Training needs of businesses in the retail industry: A business case in the United Arab Emirates
}

\author{
Ahmed Belefkiha, Arbela Grace B. Espina ${ }^{b *}$, Amabelle D. Pacana ${ }^{c,}$ Vincent L. Salas ${ }^{d}$ \\ ${ }^{a}$ Administration Department, Carrefour, Morroco, belefkih.ahmed@hotmail.com \\ ${ }^{b}$ Business Department, Uk College of Business and Computing, Dubai, United Arab Emirates, arbela.espina@gmail.com \\ ${ }^{c}$ Business Department, American College of Dubai, Dubai, United Arab Emirates, amabelle.pacana@acd.ac.ae \\ ${ }^{d}$ Business Department, American College of Dubai, Dubai, United Arab Emirates, vincent.salas@acd.ac.ae \\ ${ }^{*}$ Corresponding author
}

Received: 7 July 2019, revised: 22 August 2019, accepted: 5 September 2019, published: 10 September 2019.

\begin{abstract}
People in the organization are said to be an important asset. They need to be equipped with the needed skills to contribute to become abreast with the latest trends and demands in the industry. This research focused on an inquiry about how to make the retail industry employees skillful and relevant in the industry. The quantitative results have indicated the significance of training employees in terms of how well they apply the necessary skills at their workplaces. People who have been trained on various skills use the required skills to complete their jobs, which translates effectively to positive productivity, quality output, and satisfactory customer services. Apart from providing services to clients, employees are the cornerstone of productivity and implement the policies of the organization based on its mission, vision and core values. The results have also indicated that the majority of the employees lack the skills needed in executing daily activities. This study is significant in that it has proved beyond doubt that training needs analysis is the first step towards understanding the skill gap in an organization. That way, the company can create the needed measures and strategies for training to equip its employees with the necessary skills for increased production, quality, and improved customer services. This could result in a seamless operation that would significantly cut the overall cost of operations for the firm.
\end{abstract}

Keywords: TNA, Retail Industry

\section{INTRODUCTION}

Employees are the most important resources for any organization, especially given that they interact directly with clients on behalf of the organizations for which they work (Bratton \& Gold 2017, p. 67). As affirmed by Collings, Wood, and Szamosi (2018), employees provide services to clients, are the cornerstone of productivity, and implement the policies of the organization. As such, they often determine the overall success of the organization. Therefore, having a highly competent workforce that is not only motivated to attain optimum potential for each member of the team but also is equipped with the necessary skills to achieve workplace excellence, ought to be a top target for all organizations. This is necessary, especially in the contemporary business environment that is characterized by high levels of competition.

To gain a competitive edge in the market, organizations should ensure that their employees are highly skilled to perform complex tasks with high levels of efficiency and in a cost-effective manner. Implementing regular employee training programs is often an effective strategy for achieving workplace efficiency. It updates employees with the skills needed to improve on their performances both at personal and organizational levels. This is incongruent with the findings of the study by Khan and Begum (2015), which showed that employee training is an important performance improvement tool that ensures high productivity in an efficient, costeffective and safe manner. Furthermore, Galport and Azzam (2017) explained that employee training reduces the gap between actual and expected levels of the job performance of the workforce.

Nevertheless, it is imperative to understand that effective employee training programs can only be designed and implemented following the completion of a comprehensive and successful Training Need Analysis (TNA). This assertion has been supported by Nazli, Sipon, and Radzi (2014) who stated that it is often counterproductive to implement employee training programs for individuals who do not need it or to provide the wrong kind of training to employees. In the same vein, Brewster and Hegewisch (2017) explained that TNA helps to 
ensure that appropriate training is given to employees who need it, hence making sure that training resources are put to good use.

Training Need Analysis involves identifying gaps in skills among employees to develop employee training programs that can help to enhance their job performance at individual and organizational levels. Successful TNA focuses on the identification of deficiencies in skills and competencies at different levels of the organization's hierarchy to come up with appropriate programs for improving the organization's overall performance (Henrickson, Schmutz \& Manser, 2018). The dynamic nature of today's working environment, especially following the advancement in technological applications in workplaces, has exponentially increased training and development needs among employees. This is so because; employees ought to constantly update their skills, knowledge, and competence in their specific areas of operation, especially in line with the everadvancing technological applications that are relevant to their workplace responsibilities (Santos \& Costa 2016). Thence, TNA and subsequent implementation of employee training programs help to groom employees for the next level by not only enhancing their workplace competence but also giving them confidence in their abilities to perform at expected levels. Additionally, TNA enables managers of organizations to accurately identify key development areas of their employees, and implement training programs to boost productivity (Nazli et al., 2014). The main research problem for this study is the fact that the retail store industry in the United Arab Emirates (UAE) is growing at a very fast rate, and this has resulted in extreme competition. Competing with several dominant players in the retail market of the UAE such as Lulu Hypermarket, Spine Hypermarket, and Carrefour. The company under study always has an uphill task to keep its employees competent to gain a competitive advantage over its main business rivals. The company must ensure it not only diversifies its products and maintains top quality in everything it offers to consumers but also to constantly update the skills and competence of its staff to ensure top performance. Given that employees are the face of any organization since they interact with clients directly on behalf of the company Bratton and Gold (2017), it is undisputed that Ajman Hypermarket Cooperative Society has to ensure that its staff is skilled enough to perform at the top level, serve clients in a friendly and professional manner, and is innovative to come up with products and services that meet the dynamic needs of consumers.

In particular, the research seeks to answer the following questions:

1. How can organizations, operating within the UAE's retail sector use training needs analysis as a tool for designing appropriate employee training programs that are tailored towards improving the skills and competencies of their employees?

2. What are the leading training needs for employees of organizations operating within the UAE's retail sector?

3. Are there significant differences in the training needs of employees working in different departments of the UAE's retail sector?

4. What are the training programs that can be designed and implemented to meet the various training needs of employees of organizations in the UAE's retail sector?

Null hypothesis

The following are the corresponding hypotheses that were utilized in the study.

Hypothesis 1: There are no significant differences in the mean scores of the importance level of the skills to participants jobs between the group who have not been trained by the company and the group that has been trained

Hypothesis 2: There is no significant difference in the mean scores for effective use of the skills in the participants' jobs between the "Not Trained" and "Trained" groups.

Hypothesis 3: There is no significant relationship between the training status of the employees and the level of importance of the skills to their jobs.

\section{LITERATURE REVIEW}

This research study is built upon three theories. The theories are social learning theory, goal-setting theory, and need theories.

Social learning theory (SLT) was developed by Albert Bandura. The theory focuses on the analysis of learning by the way of observation and modelling (Ismail, 2017). Specifically, Ismail (2017) explained that SLT opined that people usually learn from each other through such processes as observational learning, imitation (emulation), and modelling (mentorship). With the application of this theory, it is assumed that individuals, especially in the organizational setting, can learn from each other through indirect experiences, oral persuasions, and physiological situations (Thomas \& Simpson, 2014; Harding, 2017). 
The application of social learning theory in this research study is important. The theory will be applied specifically in designing appropriate employee training programs that will help to upgrade the skills and competencies of employees at workplaces. Primarily, SLT will be adopted in implementing effective training programs that are based on the skills and competence needs of employees. These training programs will range from mentorship programs where lesser skilled and inexperienced employees will receive vital professional support from highly skilled and experienced employees who will not only guide them towards improving their performances but also allow them an opportunity to directly learn from them by observing how they work and emulating those (Akers 2017). Additionally, Cochran, Jones, Jones, and Sellers (2016) reiterated that social learning theory suggests that individuals can learn from each other through oral persuasion, observation, and imitation. Therefore, SLT will be used in the context of this research study to develop mentorship programs that will allow employees with deficiencies in skills and competencies to take instructions from the senior and highly skilled and experienced employee, hence allowing them to learn through both oral persuasions and imitation (Ismail 2017).

Goal-setting theory (GST), which was developed about half a century ago, is a widely used theory particularly in the fields of industrial and organizational psychology (Ismail, 2017). The theory focuses on work motivation. The goal-setting theory proposes that there is a direct connection between goal setting and enhanced productivity (Ismail, 2017). A goal, in the context of GST, represents the purpose of a given action and/or series of actions executed by an individual or group of people to achieve certain targets or set accomplishments. Neubert and Dyck (2016) added their voice to the concept of goal setting as explained by the goal-setting theory through a study, which showed that goal setting is a deliberate strategy for instituting stages of performance to attain certain anticipated outcomes.

Gardner, Diesen, Hogg, and Huerta (2016) affirmed that the goal-setting theory suggests that motivation is primarily sourced from the aspiration and consequential implementation of a plan to accomplish specific targets or goals. This sentiment was shared by Ismail (2017) who asserted that more often than not, an individual or a team that considers their present performance as falling short of the set targets would normally be motivated to put in more effort or change their strategies to achieve the set goals.

Therefore, the goal-setting theory will be applied in this research particularly in developing organizational goals that meet the abovementioned goals. With this, the organizations will be able to determine the difference between their current and aspired performances, and identify the gaps in skills and competencies that deter them from achieving their desired performances (through TNA) before coming up with appropriate employee training programs that would ensure improved performances.

The needs theories, as highlighted by Ismail (2017), explain that the perception of motivation for people is built upon their yearning to accomplish or satisfy certain needs. The needs theories further suggest that having unsatisfied needs would often motivate people to put in more effort to attain the desired outcomes (De Vito, Brown, Bannister, Cianci and Mujtaba 2018). It is justifiably arguable that having unsatisfied needs would often give people the willpower, vigor, and desire to work more and harder to have them satisfied.

Common among the needs theories the Maslow's Hierarchy of Need Theory. The theory was propounded by Abraham Maslow, and suggests that human needs are divided into five main segments namely: physiological needs, safety needs, belonging and love needs, esteem needs, and self-actualization needs (Singh \& Behera, 2016). Different types of human needs as mentioned above are usually captured in a pyramidal shape (see figure 1 below) with the basic needs situated at the bottom and higher needs at the top. According to this theory, the accomplishment and/or satisfaction of lower needs gives way to the satisfaction of higher-order needs (Hayashi Jr 2016). This implies that the accomplishment of higher-order needs is vigor dependent on the accomplishment of basic needs.

The findings of a study by Ozguner and Ozguner (2014), which showed that Maslow's Hierarchy of Needs Theory is useful in inspiring workers to perform at optimum levels, especially when they feel that the organization for which they work has their key interests at heart. Generally, many studies have affirmed that the behaviors and commitment of employees towards their work are influenced by many factors that are both internal and external (Schenk, 2017; Bailey, Mankin, Kelliher, \& Garavan, 2018). The key among the internal factors influencing employees' behaviors at workplaces is motivation Ismail (2017). Employees whose basic needs at their places of work have been fulfilled are likely to be more motivated than those whose needs are not fulfilled. As such, the management of organizations must embrace human resource systems that ensure employees are comfortable and satisfied with their workplaces to keep them motivated and highly engaged in their jobs. Therefore, this theory will be applied in this research study to emphasize the management of organizations to give preference to lower-level needs to higher-level needs. The lower level needs in this context would be meeting employees physiological needs, which may include giving them competitive wages, providing them fitness facilities within the organizations' premises, allowing them lunch/coffee breaks, giving them 
sponsored education vacations, and doing everything that is necessary to keep them as comfortable as possible in their workplaces. By so doing, employees will be highly effective in their places of work and achieve their optimum potential and this is likely to translate to improved individual and collective performance. When the optimum potential for each employee is attained, the organization will be able to easily identify training needs among its staff since each of them will be committed to giving their all to achieve the organization's goals. Thus, any gaps between the current and desired performance of the organization will be due to skill and competency gaps rather than laziness and lack of commitment from staff. Having this information will allow the management of the organization to design appropriate employee training programs that would bridge the gaps between the current and desired skills and competence of their workforce; hence bettering their chances of achieving competitiveness in terms of performance.

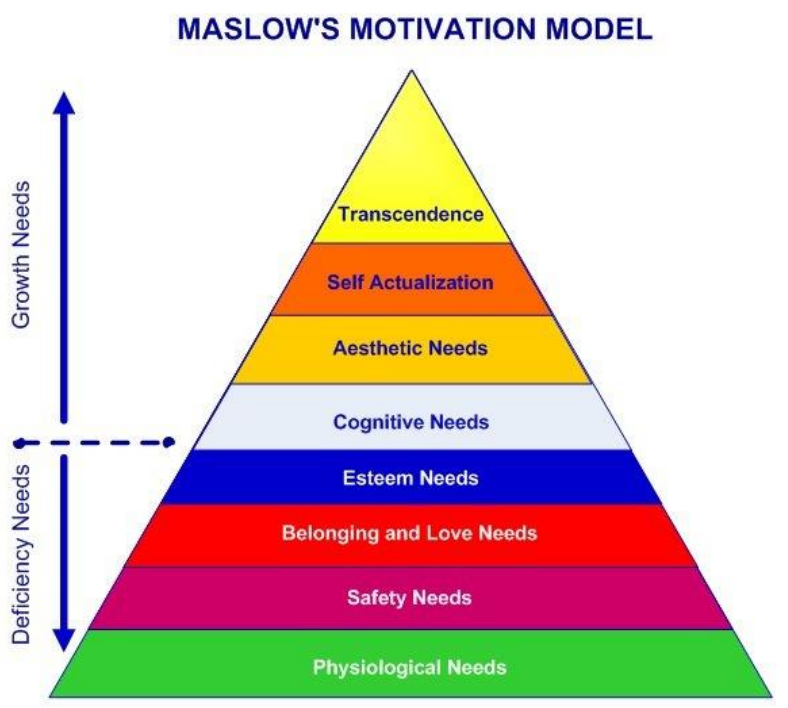

Source: www.simplypsychology.org/maslow.html

\section{Training Need Analysis}

The primary objective of conducting a training needs analysis, as outlined by Zahra, Iram, and Naeem (2014), is to provide a comprehensive understanding of training requirements of individuals and/or teams of employees in an organization. Konings and Vanormelingen (2015) asserted that TNA is conducted at three levels in an organization namely; individual, job and organizational levels.

An individual analysis is where training needs analysis is conducted on a specific person who works in each area or department of the organization (Mcllwraith 2016). The management of the organization uses performance appraisal data to assess the performance of each employee to determine inefficiencies among individual employees by comparing their actual performances against the expected performances (Ford 2014,). It targets individuals in the organization and serves to improve the performances of specific employees who are not performing at expected performance levels. Some of the strategies that are widely used in conducting individual analysis are performance appraisals, questionnaires, personal interviews, and 360 feedback (Rahimi, Mohebi, Yousefi, Kheirollahi, Saraf and Matlabi (2016). Furthermore, organizations use competency ratings to rate their managers (Dhar, 2015). Usually, subordinates, clients (customers), peers and seniors (bosses) rate managers of organizations based on their performances, and this data is used to determine whether they are performing below or above the expectations (Rahimi et al.). Additionally, Zahra (2014) affirmed that attitude surveys and assessment surveys are used in conducting a training needs analysis for individuals. The surveys help in providing an in-depth understanding of inefficiencies in terms of skills and competencies among individual employees based on their workplace performances.

Organizational analysis in the context of training needs analysis involves identifying the focus areas for training within organizations based on the deficiencies in skills and competence among employees, which is evident in below-par performance (Konings \& Vanormelingen, 2015). This kind of analysis helps in ensuring that the entire staff of the organization possess the required skills, knowledge, competence, and attitude to perform at the expected levels in order realize its mission, actualize its vision, and meet its goals and/or objectives (both short and long-term). Organizational analysis is conducted through the review of the performance data of the organization to ascertain whether the company is meeting its expected performance. If the analysis of the performance data shows that the organization's performance falls short of the expected performance, the 
management works towards determining the gaps in skills and competencies which are derailing the organization from achieving its target performance. It then uses this information to develop comprehensive employee training programs that will improve the general competence of the staff, and enhance the performance of the organization (Dhar, 2015).

Job analysis in the context of training needs analysis involves collecting and assessing information on the content and requirements of a job to achieve optimum performance (Mcllwraith, 2016). Other than determining the placement of jobs, job analysis helps to determine the necessary skills and competencies required for a person to perform at the top level in each job. By conducting a regular job analysis, organizations can accurately determine whether all their employees have the required skills to perform at the top levels in their specific workplaces. It also ensures that organizations hire employees with the best qualifications, skills, knowledge, experience, and attitude to attain exemplary results in their job positions (Ford, 2014). More importantly, job analysis enables the management of organizations to accurately determine deficiencies and inefficiencies among employees for their specific workplace responsibilities (Dhar, 2015). This, in turn, makes it easier for the organization to come up with the most appropriate employee training programs for not only enhancing the competence of each employee for his/her job but also boosting their confidence in executing their work responsibilities with the highest levels of efficiency.

\section{Forms of Employee Training}

The main objective for executing a training needs analysis, as highlighted in this research paper, is to identify shortcomings in skills and competencies among employees; and to use this information to develop the most appropriate employee training programs that would enhance their workplace performances both at individual and organizational levels (Brewster \& Hegewisch, 2017). As such, there exists an important relationship between TNA and employee training programs. Below is an analysis of some of the forms of employee training that are adoptable in organizations.

\section{Instructor-Led Training}

Instructor-led training is one of the most common forms of employee training. It takes the form of a classroom setting where the trainer (instructor) passes knowledge to the trainees (employees) through presentations (Vestergaard, Løfgren, Jessen, Petersen, Wolff, Nielsen \& Krarup, 2017). Instructor-led training is usually interactive. This implies that the trainer and trainees engage each other activity during learning. For instance, the trainees are at liberty to ask questions, which are answered either by the instructor or fellow trainees (Mardegan, Schofield and Murphy 2015). Thus, training that takes the instructor-led form is often highly effective because they are characterized by real-time engagement, and this translates to enhanced comprehension and/or understanding of the concepts taught.

Instructor-led training is usually very effective, especially when employees are taught about complex concepts and/or skills (Rhodes, 2015). The training technique allows the management of the organization to employ the services of highly-skilled and experienced instructors, who match the training levels and needs of employees to conduct a training (Min et al., 2016). Hence, employees who learn through instructor-led training programs learn from the very best and have an opportunity to ask questions and get answers from the instructor and understand complex concepts that are likely to improve their workplace performance (Min et al., 2016).

\section{E-Learning}

E-Learning in the context of employee training is a form of training where online videos, tutorials, tests, and courses are delivered to employees through the Internet Ashwin, Jose, Raghu and Reddy (2015). This form of employee training is gaining popularity in the contemporary corporate world due to its convenience and the fact that technological advancements are rampant. In affirmation of this assertion, Sethi, Lomte and Shinde (2016) stated that with computer literacy levels being at their all-time-high today and the widespread use of the Internet across the world, employees of many organizations prefer eLearning training because they are able to take these training programs at their workplace desks, on company-provided computers, or even on their personal computers.

E-Learning is equally a preferable method of employee training to other methods like mentorship and instructorled training, especially since it is easy to roll out (Ghosh, 2016). With a computing device that is connected to the Internet, eLearning is implementable. Hence, considering that many organizations have computer systems, which they use in their daily work, it follows that computers and the Internet are easily available for employees at their workplaces. Therefore, eLearning is easy and convenient in the sense that employees can take the training from anywhere provided they have computing $g$ devices that are connected to the Internet, and more importantly, the fact that many employees can take the training simultaneously and remotely. Furthermore, this 
training method is cost-effective since it does not involve logistic expenses such as accommodation costs, the cost for hiring training halls, cost for transporting trainees from their workstations to the site for training, and cost for providing special meals and allowances to employees who take the training Alhasan, Chen and Chen (2018).

\section{Coaching or Mentoring}

Coaching and/or mentorship are among the traditional employee training methods. It involves having a more experienced professional to guide a less experienced employee on how to become an exceptional professional with high levels of workplace performance (Boillat \& Elizov, 2014). Coaching entails building a strong professional relationship between the veteran employee, the mentor, the supervisor, and a more experienced professional with the lesser experienced employee at the organization.

In mentorship programs, the lesser experienced employee (mentee) receives direct guidance from the veteran employee (mentor) on how to become an excellent professional. The mentee asks questions, which are answered by the mentor. Moreover, the mentee gets to learn many things from the mentor through direct instructions, observation, and emulating (Manzi, Hirschhorn, Sherr, Chirwa, Baynes, and Awoonor-Williams 2017). Mentorship programs are mostly used in organizations as succession strategies (Huggins, 2016). This implies that the coach often trains an individual and/or group of people who he/she is assigned as a mentee(s) to become as good as him/her in a specific workplace position. The essence of mentoring is to equip the junior employees with the necessary skills, competencies, and experience to take over specific high-profile positions within the organization. Mentorship is also used in organizations to guide junior employees into excellent professionals with exemplary skills, abilities, and competence in their areas of work (Manzi et al., 2017,).

\section{Group Discussions and Activities}

Group discussions and activities are an important strategy that organizations employ to train their employees. This form of employee training involves having employees with virtually similar training needs to engage each other actively on the verge to share ideas on how to enhance their skills, competencies and general workplace performance (Amran, Yokoyama and Nishino 2016). Discussion groups usually involve teams of employees who work in a common department who are working together towards achieving common organizational goals both in the short and long term. The discussion sessions as well as activities can either be facilitated by instructors and/or supervisors or may be conducted among peers (Boyd, Pennebaker, Ferrell and Georgiev 2015, p. 7). When the group discussions are instructor-led, then the training is organized in the sense that the team of employees works under the instructor to share ideas on specific issues that affect their workplace performances. On the other hand, when the group discussions and activities are conducted among peers, employees are at liberty to ask each other all forms of questions and receive responses from their colleagues on how best to improve their skills and performances (Northridge et al., 2017). Either way, employees get to learn from each other as well as their instructor when they engage proactively in organized group discussions and activities. According to Joshi, Ganjiwale, Varma, Singh, Modi, and Singh (2017), group discussions and activities as an employee training programs are best used for organizational challenges that require collaborative approaches to achieve enhanced team competence and general organizational performance.

\section{Hands-On-Training}

Stock, Tebest, Westermann, Samuel, Strohbücker, Stosch, Wenchel and Redaèlli (2016) defined hands-ontraining (HOT) as a training program in which employees get to learn on how best to execute their workplace responsibilities by actually executing them. HOT is an experimental training program where learning is made as realistic as possible as employees learn by doing what they are required to do in their workstations. Handson-training is conducted directly on the job and helps employees to fit perfectly into their current workplace responsibilities (Coleman 2018). The training further enhances their professional skills (Knudsen, Nawrotzki, Schmiedl, Mühlfeld, Kruschinski and Ochs 2018), especially given that it is built upon the principle of "practice makes perfect." As such, the more employees get to interact with their workplaces the more they get to understand what is expected of them, and the more they perfect their skills and competence in terms of service delivery and workplace performance.

\section{On-The-Job Training}

On-the-job training (OJT) involves having newly hired employees as well as employees who have been assigned new positions and work responsibilities to watch their colleagues and supervisors and learn from them by emulating what they do to achieve the desired performances Alexander, Ford, Raghavendra, and Clark (2017). OJT helps new hires in the organizations to cope with their new workstations particularly by allowing 
them to learn from their colleagues, supervisors, and managers as they continue executing their job responsibilities in their new workstations and positions. The training method also allows new hires to share their concerns with other relevant members of staff, ask them questions regarding their jobs, and acquire more skills and competencies as they work in their jobs. Cabrales, Dolado, and Mora (2014) state that on-the-job training includes apprenticeship and self-directed learning where employees are highly motivated to learn by participating actively in executing their duties at their new workstations and positions. Generally, OJT enables employees to learn while working. Takechi, Sugihara, Matsumoto, and Yamada (2018), which is why it is an important training strategy as it provides an opportunity for them to advance their skills and improve their experience while working in their workstations (Tsai, Lee, Lin, Lee-Hsieh and Mills 2015).

\section{Training Needs Analysis and Organizational Performance}

Training needs analysis has a significant, positive impact on the performance of organizations. Below are some of the benefits of TNA about enhancing organizational performance.

Enhanced Productivity. Training needs analysis helps organizations to identify the gaps in skills and competencies among their staff both at individual and team levels. After accurate identification of these gaps, the organizations design the most appropriate training programs that would bridge in the gaps. This implies that the implemented training programs help to enhance the skills and competencies of employees, especially their areas of inefficiencies (Alhasan et al. 2018). As such, the employees become more skilled, competent, experienced and engaged in the workplaces; and this translates to improved productivity. Specifically, highly skilled, competent, engaged, and experienced employees tend to be more productive than those who are not (Dhar 2015). Additionally, Kim and Ployhart (2014) explained that employees who are taken through appropriate training programs that are based on comprehensive training need analyses to tend to be more engaged and committed their workplaces; hence, they put in discretionary effort in their jobs to achieve high performances and optimum productivity.

Reduced Employee Turnover. Training needs analysis helps to enhance employee satisfaction in their workplaces. According to Beynon, Jones, Pickernell, and Packham (2015), organizations that conduct regular training needs analysis to implement objective and appropriate training programs that enhance the skills and competencies of employees as necessary to achieve high performance. The training programs help to improve the confidence of employees in executing their workplace responsibilities at the top professional level, a factor that in turn makes them satisfied at their workplaces. Employees who are satisfied at their workplaces usually do not want to quit their jobs, and this reduces the levels of employee turnover in organizations. Furthermore, as confirmed by Shuck, Twyford, Reio Jr. and Shuck (2014), training needs analyses that culminate into effective training programs to make employees feel that the organization cares more about their wellbeing and career growth and development than profitability. This subsequently makes them commit their efforts and minds to the organization as they tend to think that the organization does not put its interests above their interests. In the same vein, Cloutier, Felusiak, Hill, and Pemberton-Jones (2015) stated that employees usually feel that they owe long-term service to organizations that have sponsored their training. The employees feel that since the organizations have put in resources to advance their skills and competencies in their areas of work, they need to pay their employers back by providing them with exemplary and long-term service. As such, they would not be in haste to quit their jobs in organizations that have contributed to their career growth and development by taking them through appropriate training programs. Retaining highly skilled, talented, competent and experienced employees at the organization for long periods leads to improved organizational performance both in the short and long term Ibidunn, Osibanjo, Adeniji, Salau and Falola ( 2015).

Enhanced Career and Talent Development. Training needs analysis is meant to identify the training needs of employees to develop the most appropriate training programs that would help them enhance their skills and competencies (Nazli et al. 2014). This means that employees get an opportunity to advance their skills and competencies in terms of service delivery and workplace performance following the implementation of appropriate training programs that have been designed based on TNA. The training programs, which may include mentorship, on-the-job training, hands-on training, group discussions, and activities, eLearning, and instructor-led training among others help employees to develop their talents and grow their careers. This eventually enables the organization to come up with a team that comprises of employees with incredible abilities, exceptional talents, and amazing workplace experiences that can propel the organization towards high performance.

Improved Competitiveness. It is the target of any organization to gain a competitive edge over its business rivals both in the local and international markets. One of the key factors that determine the competitiveness of organizations is the skills and competencies of employees (Ahmedova, 2015). An organization whose staff 
comprises highly skilled, competent and talented employees tends to provide quality services to its clients. It also has high levels of innovativeness, which enable it to come up with the best solutions for the organizational challenges it experiences and develops the best products that satisfy the dynamic needs of clients. Generally, such organizations are boast of better competitiveness than their rivals, and this helps them to enjoy enhanced customer retention and/or loyalty; a factor that significantly enhances the organization's performances in terms of expanded clientele, improved sales, and enhanced profitability (Spetic, Kozak and Vidal 2016).

\section{METHODS}

\section{Research Design}

The research study combined both qualitative and quantitative research techniques). Here, the researchers employed a survey using a standardized questionnaire and personal interview of the selected populace. This was conducted exclusively among employees of a big retail store in Ajman, involved 90 respondents. Further, the survey was conducted through an online platform. Specifically, the researcher sent the questionnaire to selected respondents through their E-mail accounts and then communicated with them individually.

\section{Target Population and Sample Size}

The target population was the employees of a Hypermarket. They were categorized into those who had undergone employee training and those who had not trained. The total target population was 640: 421 male and 199 female employees. The number of participants selected from the target population was 90 employees: 35 females and 55 males. The summary of the target population and the sample size are summarized in the following table.

Table 1. Target population and sample size selected from the target population.

\begin{tabular}{ccc}
\hline Gender & Target Population & Sample Size \\
\hline Female & 219 & 35 \\
Male & 421 & 55 \\
\hline TOTAL & 640 & 90 \\
\hline
\end{tabular}

Data from the filled-in questionnaire was arranged, tabulated, and analyzed by the researcher to derive objective results. A descriptive and inferential statistical tool for data analysis, particularly the Statistical Package for Social Science (SPSS) software, was used for analyzing data for this research study. Through the descriptive aspect of the SPSS software, the researcher was able to generate charts and tables that represented demographic information of participants of this research study in an accurate and easy-to-understand manner. On the other hand, the inferential statistical aspect of the SPSS software was used for making accurate predictions on the trends of the topic of study based on the research questions and hypotheses. For effective analysis and presentation of the data, ANOVA and Pearson's Chi-Square were adopted as the inferential statistical tools.

\section{ANALYSIS AND RESULTS}

\section{Demographic Information}

Demographic information of the participants included gender, work tenure, work position, and training status. In terms of gender, the participants were categorized into male and female. Based on the work tenure, the participants were grouped into those who have worked for less than 5 years with the company, between 5 and 10 years and those who have worked for more than 10 years. In terms of work position, the study subjects were divided into those who worked in managerial positions in head office, managerial position in operation, supervisor/team leadership position, food department, non-food department, and service department.

There was a total of 90 employees drawn from the employee population to participate in the study. From this sample size, $61.1 \%(n=55)$ were males while $38.9 \%(n=35)$ were females. The sample size was a representation of the entire population in all departments based on the information they provided during the data collection process. 
Table 2. Descriptive results showing frequency

\begin{tabular}{|c|c|c|c|c|c|}
\hline & & Frequency & Percent & Valid Percent & Cumulative Percent \\
\hline & Male & 55 & 61.1 & 61.1 & 61.1 \\
\hline \multirow[t]{2}{*}{ Valid } & Female & 35 & 38.9 & 38.9 & 100.0 \\
\hline & Total & 90 & 100.0 & 100.0 & \\
\hline
\end{tabular}

Table 3.Descriptive results showing frequency

\begin{tabular}{cccccc}
\multicolumn{5}{c}{ Distribution of the participants' work tenure with the company } \\
\hline \multirow{4}{*}{ Valid } & Frequency & Percent & Valid Percent & Cumulative Percent \\
& 5 5 Years & 59 & 65.6 & 65.6 & 65.6 \\
& $5-10$ Years & 23 & 25.6 & 25.6 & 91.1 \\
& > 10 Years & 8 & 8.9 & 8.9 & 100.0 \\
\hline
\end{tabular}

Table 3 above shows the frequency distribution of the participants' work tenure. Out of the 90 study subjects, $65.6 \%(n=59)$ had a work tenure of less than 5 years with the company, 25.6\% $(n=23)$ had worked with the company for between 5 and 10 years while $8.9 \%(n=8)$ had worked with the company for more than 10 years. From the results, it can be concluded that the majority of the employees at the firm have worked for less than 5 years.

Table 4.Descriptive results showing frequency.

Distribution of the participants' work position in the company

\begin{tabular}{|c|c|c|c|c|c|}
\hline & & Frequency & Percent & Valid Percent & $\begin{array}{c}\text { Cumulative } \\
\text { Percent }\end{array}$ \\
\hline \multirow{7}{*}{ Valid } & Managerial(Head Office) & 7 & 7.8 & 7.8 & 7.8 \\
\hline & Managerial (Operation) & 6 & 6.7 & 6.7 & 14.4 \\
\hline & Supervisor/Team Leader & 5 & 5.6 & 5.6 & 20.0 \\
\hline & Food Department & 16 & 17.8 & 17.8 & 37.8 \\
\hline & Non-Food Department & 34 & 37.8 & 37.8 & 75.6 \\
\hline & Service Department & 22 & 24.4 & 24.4 & 100.0 \\
\hline & Total & 90 & 100.0 & 100.0 & \\
\hline
\end{tabular}

From the table $4,7.8 \%(n=7)$ of the participants are working in the managerial position at the company's head office, $6.7 \%(n=6)$ are working in the managerial positions in the operational department, and $5.6 \%(n=5)$ work as supervisors or team leaders. Furthermore, 17.8\% $(n=16)$ work in the food department, $37.8(n=34)$ work in the company's non-food department while $24.4 \%(n=22)$ work in the service department. From the results, the majority of the participants are working in the food-department while approximately $80 \%(n=72)$ of the study population were working in non-managerial and non-supervisory positions, which is the unexpected trend in a company context.

Table 5. Descriptive results showing frequency.

Whether the participants have undergone training since they were employed in this company

\begin{tabular}{cccccc}
\hline & & Frequency & Percent & Valid Percent & Cumulative Percent \\
\hline \multirow{2}{*}{ Valid } & No & 57 & 63.3 & 63.3 & 63.3 \\
& Yes & 33 & 36.7 & 36.7 & 100.0 \\
& Total & 90 & 100.0 & 100.0 & \\
\hline
\end{tabular}

Table 5 represents the training status of the employee; that is, whether they had been provided with the necessary training by the company to improve their productivity and ability to provide satisfactory customer services. The majority of the employees, that is, $63.3 \%(n=57)$ have not been trained further by the company to meet the production and customer service needs. These employees depend on their professional and personal skills and experiences rather than pieces of training offered to update the skills with the modern market demands. However, $36.7 \%(n=33)$ has been offered the necessary training, which is a considerably good ratio to the total employee population, especially when most trained individuals are in the managerial and team leadership positions. 


\section{One-Way ANOVA Results and Analysis}

One-way analysis of variance (ANOVA) is one of the inferential statistical tools used to analyze the numerical data collected from the study subjects. The tool is essential to determine whether there is a significant difference in the means of two or more groups. The training status of the employees is very important in the way they execute their responsibilities at various workplaces. From the knowledge developed through literature review, many scholars recommend the training of employees to improve their productivity in terms of quality and satisfactory customer services. Thus, it is predicted that the training status of an employ defines how important various skills are to their job. As such, the participants were categorized into two: those who have been trained by the company and those who have not been trained. The participants were also asked to provide an overall rating of over 10 on a 1-10 scale to estimate the importance level of the 7 skills to their job.

Taking the training status (Have you undergone training since you were employed in this company?) as the independent variable and the rated levels of the skills importance to their job (Rate the importance level of the above skills to your job over 10) as the dependent variable, one-way ANOVA was conducted to determine if the importance level of the skills to their jobs differ based on whether they have been trained by the company to adopt those skills or not. The results were presented in the following tables.

Table 6.Descriptive statistics.

Rate the importance level of the above skills to your job over 10

\begin{tabular}{|c|c|c|c|c|c|c|c|c|}
\hline & \multirow[t]{2}{*}{$\mathrm{N}$} & \multirow[t]{2}{*}{ Mean } & \multirow[t]{2}{*}{ Std. Deviation } & \multirow[t]{2}{*}{ Std.Error } & \multicolumn{2}{|c|}{$\begin{array}{c}95 \% \text { Confidence Interval } \\
\text { for Mean }\end{array}$} & \multirow[t]{2}{*}{ Minimum } & \multirow[t]{2}{*}{ Maximum } \\
\hline & & & & & $\begin{array}{l}\text { Lower } \\
\text { Bound }\end{array}$ & $\begin{array}{l}\text { Upper } \\
\text { Bound }\end{array}$ & & \\
\hline Not Trained & 57 & 3.42 & 1.051 & .139 & 3.14 & 3.70 & 2 & 7 \\
\hline Trained & 33 & 7.61 & 1.968 & .343 & 6.91 & 8.30 & 2 & 10 \\
\hline Total & 90 & 4.96 & 2.490 & .262 & 4.43 & 5.48 & 2 & 10 \\
\hline
\end{tabular}

Table 6 above shows the descriptive information of the participants based on their training status and the mean importance level of the skills to their jobs. Of the total 90 participants, 57 had not received any personnel training while 33 had received the training. Among those who have not been trained by Ajman, the mean score and standard deviation for the importance of the skill to their jobs is Mean $=3.42$ and SD $=1.051$ respectively. For those who have been trained, the mean score and standard deviation for the skills important to their jobs are Mean $=7.61$ and $\mathrm{SD}=1.968$ respectively. From the descriptive table, it can be seen that the mean scores for the two groups (Not Trained vs. Trained) are different. However, to determine whether the difference was significant, the following ANOVA table was run and the results obtained.

Table 7. ANOVA Analysis I

\begin{tabular}{cccccc}
\multicolumn{7}{c}{ Rate the importance level of the above skills to your job over 10 } \\
\hline & Sum of Squares & df & Mean Square & F & Sig. \\
\hline Between Groups & 366.049 & 1 & 366.049 & 173.395 & .000 \\
Within Groups & 185.774 & 88 & 2.111 & & \\
\hline Total & 551.822 & 89 & & & \\
\hline
\end{tabular}

The above ANOVA table shows that there is a significant difference in the mean scores of the importance level of the skills to participants jobs between the group who have not been trained by the company and the group that has been trained, $F(1,88)=173.395, p<0.001$. The mean score of the trained group $(7.61)$ is higher than the mean score of the untrained group (3.42). From the results, it can be concluded that employees who are trained in various skills find those skills more useful in executing their jobs than employees who have not been trained in various working skills. These observations are supported by Brewster and Hegewisch (2017, p. 21) who argue that TNA assists in ensuring that appropriate training is given to employees who need it so that they can apply the skills at their workplaces.

Personal-appraisal is an important aspect of employee perceptions and hence satisfaction with their jobs. It is predicted that the effectiveness with which the employees perform the various skills assessed in the questionnaire is based on whether an employee has been trained by the company or not. Therefore, taking training status (Not Trained vs. Trained) as the independent variable and effectiveness level (Using the following 1-10 scale, provide an overall score over 10 for the effectiveness with which you perform the above skills) as the dependent variable, another one-way ANOVA was conducted. The main objective was to determine whether 
the effectiveness score with which participants performed the skills differed between "Trained" and "Not Trained" groups.

Table 8. Descriptive statistics.

Rate the importance level of the above skills to your job over 10

\begin{tabular}{|c|c|c|c|c|c|c|c|c|}
\hline & \multirow[t]{2}{*}{$\mathrm{N}$} & \multirow[t]{2}{*}{ Mean } & \multirow[t]{2}{*}{ Std. Deviation } & \multirow[t]{2}{*}{$\begin{array}{l}\text { Std. } \\
\text { Error }\end{array}$} & \multicolumn{2}{|c|}{$\begin{array}{l}\text { 95\% Confidence Interval } \\
\text { for Mean }\end{array}$} & \multirow[t]{2}{*}{ Minimum } & \multirow[t]{2}{*}{ Maximum } \\
\hline & & & & & $\begin{array}{l}\text { Lower } \\
\text { Bound }\end{array}$ & $\begin{array}{l}\text { Upper } \\
\text { Bound }\end{array}$ & & \\
\hline No & 57 & 3.35 & 1.343 & .178 & 2.99 & 3.71 & 2 & 9 \\
\hline Yes & 33 & 7.55 & 1.970 & .343 & 6.85 & 8.24 & 2 & 10 \\
\hline Total & 90 & 4.89 & 2.581 & .272 & 4.35 & 5.43 & 2 & 10 \\
\hline
\end{tabular}

Table 8 above shows the descriptive information of the participants based on their training status and the mean score for the effective use of skills in their jobs. From the total participants, 57 had not received any personnel training while 33 had received the training. Among those who have not been trained, the mean score and standard deviation for the effective use of skills in performing their jobs are Mean $=3.35$ and SD $=1.343$ respectively. Among the untrained group, the mean score and standard deviation for effective use of skills in performing their jobs are Mean $=7.55$ and $S D=1.97$ respectively. The results show that the mean scores for the two groups (Not Trained vs. Trained) are different. However, to determine whether the difference was significant, the ANOVA table was run and the results obtained.

Table 9. ANOVA Analysis II

Rate the importance level of the above skills to your job over 10

\begin{tabular}{lccccc}
\hline & Sum of Squares & df & Mean Square & F & Sig. \\
\hline Between Groups & 367.725 & 1 & 367.725 & 143.716 & .000 \\
Within Groups & 225.164 & 88 & 2.559 & & \\
Total & 592.889 & 89 & & & \\
\hline
\end{tabular}

The above ANOVA table 9 shows that there is a significant difference in the mean scores for effective use of the skills in the participants' jobs between the "Not Trained" and "Trained" groups, $F(1,88)=143.716, p<0.001$. The mean score of the trained group (7.55) is higher than the mean score of the untrained group (3.35). From the results, it can be concluded that employees who are trained in various skills use the skills more effectively when executing their jobs than employees who have not been trained.

In support of these findings, Santos and Costa (2016, p. 756), stated that employees ought to constantly update their skills, knowledge, and competence in their specific areas of operation, especially in line with the everadvancing technological applications that are relevant to their workplace responsibilities. Furthermore, the significant difference in the level of effectiveness for the use of skills among employees signifies a gap in handson skills. According to Razack and Upadhyay (2017, p. 51), Ajman Hypermarket Cooperative Society, just like other companies in the retail sector of the UAE, experiences significant lack of skills among its employees. Thus, the majority of employees are unable to use the necessary skills effectively at their workplaces. This triggers the need for training among employees to close the skill gap and achieve the desired levels for competencies essential for productivity and customer services (Jensen 2016, p. 67).

\section{Pearson's Chi-Square}

To confirm the significance of training among employees, this study was interested in assessing the relationship between the training status (Not Trained vs. Trained) of the participant and the importance level of the necessary skills to their work. Therefore, a Pearson's Chi-Square test was conducted using the training status (Not Trained vs. Trained) variable and the various skills (Working Skills, Communication Skills, People Skills, Leader Skills, Customer Skills, Business Skills, and Analytical Skills) variables. There was a significant effect on the test between Training Status (Not Trained vs. Trained) for all the 7 skills variables as shown in the results obtained with the working skills below.

The cross-tab table above shows the interaction between the Training Status (Not Trained vs. Trained) variables and the importance level of the skills (Not at all vs. Slightly Important vs. Moderately Important vs. Very Important vs. Extremely Important). About $88.9 \%$ of the "Not trained" group believed that the skills were less important to their jobs. On the other hand, about $88.9 \%$ of the "Trained" group believed that the working skills were important for their jobs. The results suggest that the majority of people who are untrained do not find the skills useful to 
their jobs as opposed to most trained people who believe the skills were important to their jobs. The following Pearson's Chi-Square test table determined whether the relationship is significant.

Table 10.Crosstab

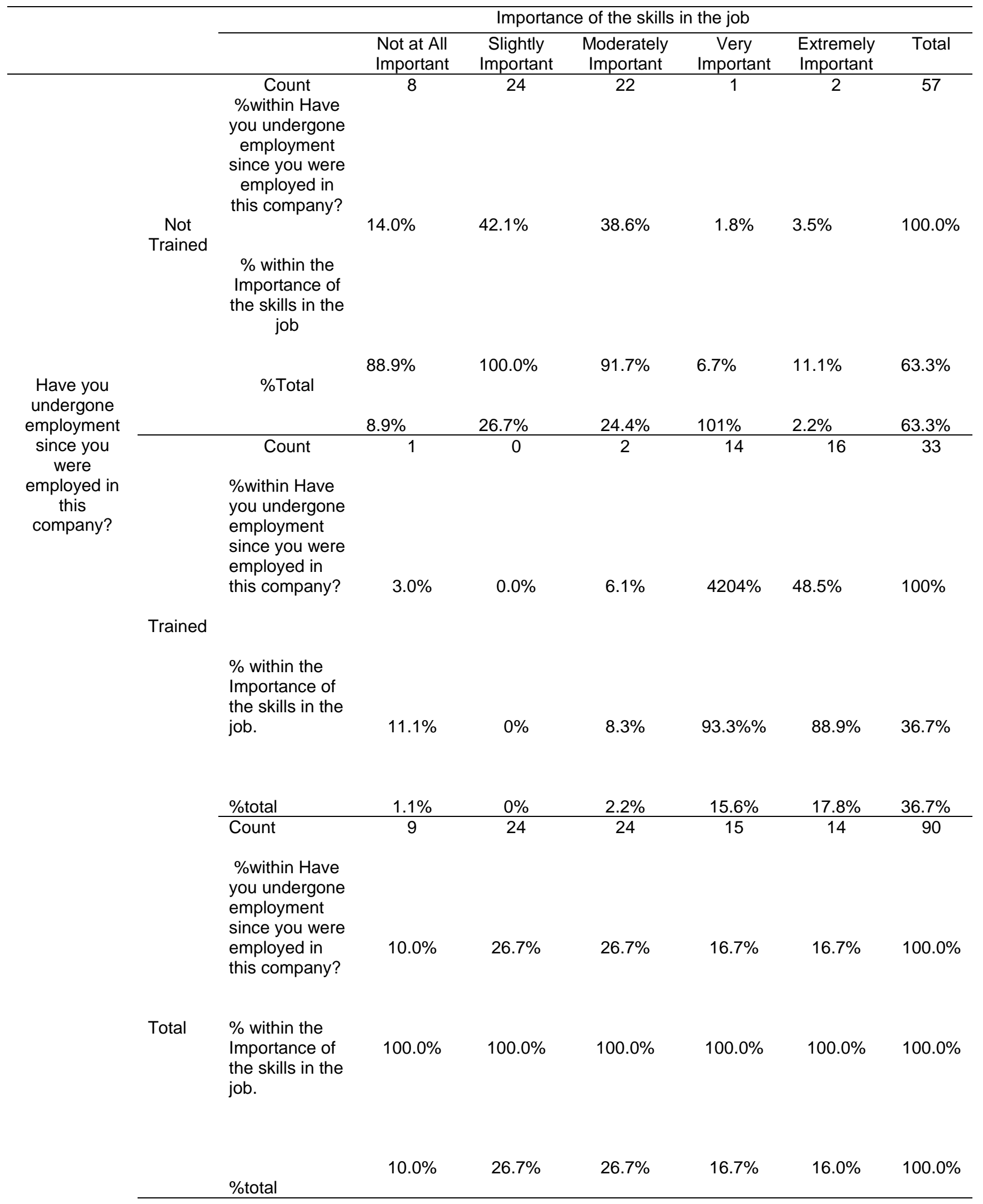


Table 11. Pearson's Chi-Square tests results

\begin{tabular}{cccc}
\hline & Value & df & Asymp. Sig. (2-sided) \\
\hline Pearson Chi-Square & $66.603 a$ & 4 & .000 \\
Likelihood Ratio & 78.335 & 4 & .000 \\
Linear-by-Linear Association & 48.282 & 1 & .000 \\
\hline N of Valid Cases & 90 & &
\end{tabular}

A.1 cells (10.0\%) have expected count less than 5 . The minimum expected count is 3.30 .

Table 12. Symmetric measures for the Phi and Cramer's V test

\begin{tabular}{llrr} 
& & Value & Approx. Sig. \\
\hline Nominal by Nominal & Phi & .860 & .000 \\
NNof Valid Cases & Cramer's V & .860 & .000 \\
\hline
\end{tabular}

a. Not assuming the null hypothesis.

b. Using the asymptotic standard error assuming the null hypothesis.

From the Chi-Square test table, there is a significant relationship between the training status of the employees and the level of importance of the skills to their jobs $x(4)=60.603, p<0.001$. The Phi and Cramer's $V$ tests in table 12 show the strength of relationship between the two variables, $86 \%(0.86)$. The strength of association or relationship is highly significant, $p<0.001$. Other tests also indicate strong association with a significant value of $p<0.001$. Individuals who are trained use the skills more significantly in their workplace than individuals who have not received the training on those skills. The results suggest that training?. These findings are supported by Beynon et al. (2015, p.147) in their assertion that training employees improves their satisfaction level because they are able to use learned skills in their workplaces. In further examination, Nazli et al. (2014, p. 580) argues that training needs analysis practices are meant to identify the needs of employees in terms of skills development, which is a prerequisite for employee competencies.

\section{CONCLUSIONS}

This study was aimed at assessing the training need analysis for the local retail sector, located in Ajman UAE as the case study company. The rationale behind the study is the significant gap in employee skills in the UAE's retail sector, which works against the growth of businesses in the industry. This is due to the poor productivity of the employees and the inability to provide effective customer services. To understand the content, the study analysis has been integrated with relevant theories such as social learning theory, goal-setting theory, and needs theory. The three theories help in explaining the significance of social learning among employees, the necessity of setting goals for employee training and why training needs analysis is essential in identifying the skill needs to launch training.

During the training need analysis, the company should conduct an analysis based on the following three key areas. These include individual analysis, organizational analysis and job position analysis. These three analyses integrate the skills acquired by the human resources to the specific needs in their workplace and hence achieving the organization's goals. Consequently, the company will determine the best training approach for the employees from the following list: instructor-led training, e-learning, coaching/mentoring, group discussion, hands-on training, and on-the-job training. There are several benefits of training needs analysis that include increased productivity, reduced employee turnover, enhanced career and talent development, and improved competitiveness. This knowledge is supported by the quantitative findings of this study.

Employees are the most important resources for a company because they influence the efficiency of other factors of production and business operations. The quantitative results have indicated the significance of training employees in terms of how well they apply the necessary skills at their workplaces. People who have been trained on various skills use the required skills to complete their jobs, which translates effectively to positive productivity, quality output, and satisfactory customer services. Apart from providing services to clients, employees are the cornerstone of productivity and implement the policies of the organization based on its mission, vision and core values. The results have also indicated that majority of the employees lack skills needed in executing daily activities. This study is significant in that it has proved beyond doubt that training needs analysis is the first step towards understanding the skill gap in an organization. That way, the company can create the needed measures and strategies for training to equip its employees with the necessary skills for increased production, quality, and improved customer services. This could result in a seamless operation that would significantly cut the overall cost of operations for the firm. 


\section{ACKNOWLEDGMENTS}

We would like to thank all the participants of this research for their valuable contribution to the completion of this research.

\section{REFERENCES}

Abdulkadiroğlu, A., Angrist, J.D., Narita, Y. \& Pathak, P.A. (2017). Research design meets market design: Using centralized assignment for impact evaluation. Econometrical, 85(5), 1373-1432.

Ahmedova, S. (2015). Factors for increasing the competitiveness of small and medium-sized enterprises (SMEs) in Bulgaria. Procedia-Social and Behavioral Sciences, 195, 1104-1112.

Akers, R. (2017). Social learning and social structure: A general theory of crime and deviance. Routledge.

Albrecht, S.L., Bakker, A.B., Gruman, J.A., Macey, W.H. \& Saks, A.M. (2015). Employee engagement, human resource management practices and competitive advantage: An integrated approach. Journal of Organizational Effectiveness: People and Performance, 2(1), 7-35.

Alexander, J., Ford, J., Raghavendra, P. \& Clark, J. (2017). Nature and extent of on-the-job training for employees with an intellectual disability: a pilot study. Research and Practice in Intellectual and Developmental Disabilities, 1-11. https://doi.org/10.1080/23297018.2017.1359661

Aydelotte, W.O., Fogel, R.W. \& Bogue, A.G. (2015). The dimensions of quantitative research in history. Princeton University Press

Bailey, C., Mankin, D., Kelliher, C. \& Garavan, T. (2018). Strategic human resource management. Oxford University Press

Bakar, K.A.A. (2015). The Study of Training Needs Analysis (TNA). Practice in Manufacturing Companies in Malaysia (Doctoral dissertation, Universiti Teknologi Malaysia). http://eprints.utm.my/id/eprint/53956/1/KhairulAsrafMFM2015.pdf

Barnham, C. (2015). Quantitative and qualitative research: Perceptual foundations. International Journal of Market Research, 57 (6), 837-854.

Beynon, M.J., Jones, P., Pickernell, D. \& Packham, G. (2015). Investigating the impact of training influence on employee retention in small and medium enterprises: a regression-type classification and ranking believe simplex analysis on sparse data. Expert Systems, 32(1), 141-154. https://doi.org/10.1111/exsy.12067

Boillat, M. \& Elizov, M. (2014). Peer coaching and mentorship. In Faculty Development in the Health Professions, 159-179.

Collings, D.G., Wood, G.T. \& Szamosi, L.T. (2018). Human resource management: A critical approach. In Human Resource Management, 1-23. Routledge.

Galport, N. and Azzam, T. (2017). Evaluator training needs and competencies: A gap analysis. American Journal of Evaluation, 38(1), 80-100.

Gardner, A.K., Diesen, D.L., Hogg, D. \& Huerta, S. (2016). The impact of goal setting and goal orientation on performance during a clerkship surgical skills training program. The American Journal of Surgery, 211(2), 321-325.

Ghosh, B. (2016). Exploratory study of effects of elearning system acceptance on learning outcomes. Journal of Information Systems Applied Research, 9 (2), 13.

Hall, J.A. \& Rosenthal, R. (2018). Choosing between random-effects models in meta-analysis: Units of analysis and the generalizability of obtained results. Social and Personality Psychology Compass, e12414. https://doi.org/10.1111/spc3.12414

Holloway, K., Arcus, K. \& Orsborn, G. (2018). Training needs analysis-The essential first step for continuing professional development design. Nurse education in practice, 28, 7-12.

Kim, Y. \& Ployhart, R.E. (2014). The effects of staffing and training on firm productivity and profit growth before, during, and after the Great Recession. Journal of Applied Psychology, 99 (3), 361. https://psycnet.apa.org/doi/10.1037/a0035408

Konings, J. and Vanormelingen, S. (2015). The impact of training on productivity and wages: firm-level evidence. Review of Economics and Statistics, 97(2), 485-497.

Locke, E.A. \& Latham, G.P. (2015). Breaking the rules: a historical overview of goal-setting theory. In Advances in motivation science, 99-126. 
Manzi, A., Hirschhorn, L.R., Sherr, K., Chirwa, C., Baynes, C., \& Awoonor-Williams, J.K. (2017). Mentorship and coaching to support strengthening healthcare systems: lessons learned across the five population health implementation and training partnership projects in sub-Saharan Africa. BMC health services research, 17(3), 831. https://www.ncbi.nlm.nih.gov/pubmed/29297323

Mardegan, K.J., Schofield, M.J., \& Murphy, G.C., 2015. Comparison of an interactive CD-based and traditional instructor-led Basic Life Support skills training for nurses. Australian Critical Care, 28(3), 160-167.

Mcllwraith, A. (2016). Information security and employee behaviour: how to reduce risk through employee education, training and awareness. Routledge.

Min, M.K., Yeom, S.R., Ryu, J.H., Kim, Y.I., Park, M.R., Han, S.K., Lee, S.H., Park, S.W. \& Park, S.C. (2016 . Comparison between an instructor-led course and training using a voice advisory manikin in initial cardiopulmonary resuscitation skill acquisition. Clinical and experimental emergency medicine, 3(3), 158.

Nazli, N.N.N.N., Sipon, S., \& Radzi, H.M. (2014). Analysis of training needs in disaster preparedness. ProcediaSocial and Behavioral Sciences, 140, 576-580.

Neubert, M.J. \& Dyck, B. (2016). Developing sustainable management theory: goal-setting theory based in virtue. Management Decision, 54(2), 304-320.

Northridge, M.E., Shedlin, M., Schrimshaw, E.W., Estrada, I., De La Cruz, L., Peralta, R., Birdsall, S., Metcalf, S.S., Chakraborty, B., \& Kunzel, C. (2017). Recruitment of racial/ethnic minority older adults through community sites for focus group discussions. BMC Public Health, 17(1), p.563.

Ozguner, Z., \& Ozguner, M. (2014). A managerial point of view on the relationship between of Maslow's hierarchy of needs and Herzberg's dual factor theory. International Journal of Business and Social Science, 5(7).

Rahimi, Z., Mohebi, S., Yousefi, Z., Kheirollahi, F., Saraf, P\& and Matlabi, M. (2016). Analysis of training needs of mothers on exclusive breastfeeding: A study in health care centers. International Journal of Pediatrics, 4(12), 4089-4098.

Razack, S.S. and Upadhyay, D. (2017). Employee perception of performance management systems in the UAE: An analysis.

Rhodes, J.A. (2015). Incorporating collaborative technologies into the pedagogy of instructor-led training.

Santos, P.J.D.L., \& Costa, R.S. (2016). Workers with disabilities in sheltered employment centres: a training needs analysis. International Journal of Inclusive Education, 20(7), 756-769.

Schenk, H.W.E. (2017). The prevalence and focus of formalised Human Resource Management Practices in a sample of SMEs in the Marketing and Retail sector of South Africa. The Retail and Marketing Review, 13(2), 40-54.

Sethi, M.A., Lomte, S.S. \& Shinde, U.B. (2016). Adaptive eLearning system for visual and verbal learners. In Computing for Sustainable Global Development (INDIACom), 2016 3rd International Conference on (pp. 1302-1306). IEEE.

Shuck, B., Twyford, D., Reio Jr, T.G. \& Shuck, A. (2014). Human resource development practices and employee engagement: Examining the connection with employee turnover intentions. Human Resource Development Quarterly, 25(2), 239-270.

Singh, T. \& Behera, M.P. (2016). Application of the Maslow's hierarchy of need theory: Impacts and implications on employee's career stages. Training \& Development Journal, 7(2), 43-52.

Spetic, W., Kozak, R.A. \& Vidal, N.G. (2016). Critical factors of competitiveness for the British Columbia secondary wood products industry. Bioproducts Business, 13-31.

Stock, S., Tebest, R., Westermann, K., Samel, C., Strohbücker, B., Stosch, C., Wenchel, H.M. \& Redaèlli, M. (2016). Implementation of an innovative hands-on training to improve adherence to hygiene rules: a feasibility study. Nurse Education Today, 36, 407-411.

Takechi, H., Sugihara, Y., Matsumoto, H. \& Yamada, H. (2018). A dementia café as a bridgehead for community-inclusive care: Qualitative Analysis of observations by on-the-job training participants in a dementia café. Dementia and Geriatric Cognitive Disorders, 46(3-4), 128-139.

Thomas, K.J. \& Simpson, S.S. (2014). Social learning theory. Encyclopedia of Criminology and Criminal Justice, 4951-4963.

Tsai, P.R., Lee, T.T., Lin, H.R., Lee-Hsieh, J. \& Mills, M.E. (2015). Nurses' Perceptions of e-portfolio Use for On-the-job Training in Taiwan. CIN: Computers, Informatics, Nursing, 33(1), 21-27. 
(C) 2019 the Authors. Journal of Research in Emerging Markets, 2019, 1 (3).

Vestergaard, L.D., Løfgren, B., Jessen, C.L., Petersen, C.B., Wolff, A., Nielsen, H.V\& Krarup, N.H. (2017). A comparison of pediatric basic life support self-led and instructor-led training among nurses. European Journal of Emergency Medicine, 24(1), 60-66.

Zahra, S., Iram, A. \& Naeem, H. (2014). Employee training and its effect on employees' job motivation and commitment: Developing and proposing a conceptual model. IOSR Journal of Business and Management, 16(9), 60-68. 